\title{
Regionalismo abstracto y representación simbólica de la nación en la literatura latinoamericana de la región
}

\author{
Friedhelm Schmidt-Welle* \\ INSTITUTO IBERO-AMERICANO, BERLÍN, ALEMANIA
}

En Latinoamérica, la noción de "regionalismo literario" se aplica a dos corrientes literarias: la literatura de una cierta región con sus localismos, por una parte, y la llamada "novela regional" o "regionalista" que incluye la narrativa indianista e indigenista. El apogeo de esta última corresponde a las primeras tres décadas del siglo xx. En el artículo, se enfatiza el hecho de que la novela regional o regionalista, al contrario de la literatura local de una región, es una representación simbólica de la nación y, en este sentido, representa una alegoría nacional.

(Alegoría nacional, literatura latinoamericana, nación, novela, regionalismo)

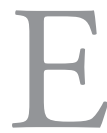

n la crítica literaria latinoamericana existen dos nociones de literatura regionalista a primera vista bastante diferentes. Por una parte, se habla de literatura regional o regionalista refiriéndose a un conjunto de literatura que se produce en ciertas regiones interiores de los países latinoamericanos o que trata de las culturas de las provincias o regiones interiores, sobre todo de la vida en el campo, distinguiéndola de la vida urbana en general o de la vida en las metrópolis o capitales en particular.

Esta corriente se ocupa de temas casi exclusivamente locales, es decir, no se trata de una literatura regional con un afán universalista en el sentido en que la define Tolstoi, sino de una literatura regionalista que pone énfasis en las características específicas de las culturas

*schmidt-welle@iai.spk-berlin.de 
locales. Esta literatura regionalista no ha despertado mucho interés en la crítica, y hasta hoy no se ha definido un corpus de la misma. Existen pocos intentos de documentarla en textos de críticos que en su mayoría trabajan en universidades de la misma región como, por ejemplo, el volumen editado por Gloria Videla de Rivero y Marta Elena Castellino sobre la literatura de las regiones $\operatorname{argentinas~}^{1} \mathrm{o}$ los ensayos de Joaquim Inojosa ${ }^{2}$ sobre el regionalismo brasileño. También hay intentos de documentar las literaturas regionales en un contexto nacional como en el caso de la revista cultural mexicana Blanco Movil que ha dedicado secciones monográficas de varios números a la literatura de las entidades federativas mexicanas. Pero en todos estos casos se trata de ensayos aislados. En general, la crítica profesional ha prestado muy poca atención a esta corriente de la literatura regionalista.

La otra corriente de literatura regionalista es la que se ha denominado "regionalismo", 3 "novela de la tierra" $\mathrm{o}$ "novela criollista". 5 Esta literatura sí ha merecido el interés de la crítica, y forma parte del canon de la literatura latinoamericana a pesar de la crítica feroz por parte de algunos escritores y críticos literarios a partir de los sesenta del siglo pasado que la calificaron como "novela impura" o "novela primitiva" y la consideraron como un obstáculo para la deseada modernización del sistema literario. ${ }^{6}$ Este regionalismo litera-

${ }^{1}$ Gloria Videla de Rivero, Marta Elena Castellino, eds., Literatura de las regiones argentinas, Mendoza, Universidad Nacional de Cuyo, 2004.

${ }^{2}$ Joaquim Inojosa, Conferências I: O regionalismo na literatura brasileira, Río de Janeiro, Livraria Editora Cátedra, 1986.

${ }^{3}$ José Miguel Oviedo, Historia de la literatura hispanoamericana. 3. Postmodernismo, vanguardia, regionalismo, Madrid, Alianza, 2001.

${ }^{4}$ Carlos J. Alonso, The Spanish American Regional Novel. Modernity and Autochthony, Cambridge, Cambridge University Press, 1990.

${ }^{5}$ Carlos J. Alonso, "The Criollista Novel”, en Roberto González Echevarría, Enrique Pupo-Walker, eds., The Cambridge History of Latin American Literature. Volume 2: The Twentieth Century, Cambridge, Nueva York, Melbourne, Cambridge University Press, 1996, 195-212.

${ }^{6}$ Carlos Fuentes, La nueva novela hispanoamericana, México, Joaquín Mortiz, 1969; Mario Vargas Llosa, "Novela primitiva y novela de creación en América Latina”, en Revista de la Universidad de México, 23, 10, 1969, 29-36. Cfr., para una crítica de estas posturas, Efrain Kristal, "Del indigenismo a la narrativa urbana en el Perú", en Revista de Critica Literia Latinoamericana, 14, 27, 1988, 57-74 y Friedhelm Schmidt, Stimmen 
rio tiene sus raíces en obras del siglo XIX, sobre todo en los cuadros de costumbres y algunas novelas históricas, pero su auge data de las primeras tres décadas del siglo Xx, cuando en algunos países hispanoamericanos se convierte en la corriente literaria dominante. Por lo general, se incluyen en ella ciertas obras de la novela social de esta época, pero también el indigenismo, la novela de la Revolución mexicana y la literatura nordestina del Brasil.

El corpus de este regionalismo se ha definido y analizado ampliamente, e incluso se han destacado obras "clásicas" del mismo, ante todo tres novelas que aparecen en tan sólo cinco años: La vorágine (1924) del colombiano José Eustasio Rivera; Don Segundo Sombra (1926) del argentino Ricardo Güiraldes; y Doña Bárbara (1929) del venezolano Rómulo Gallegos.

En este artículo, analizaré las características más importantes de estas dos corrientes de la literatura regionalista, y al final añadiré algunas propuestas con respecto a la interpretación de textos literarios más recientes que, por una parte, se inscriben en la misma tradición y, por otra, la cuestionan mediante la introducción de nuevas formas, estilos literarios; u otros enfoques sobre la región y sus relaciones internas, es decir, dentro de la nación, o sus relaciones externas, las internacionales.

En América Latina, la problemática de la literatura regional o regionalista surge con la independencia. La identidad nacional y la diferenciación cultural con respecto a la Colonia y con respecto a otros países latinoamericanos se refleja en distintas formas de literaturas regionales que consideran la confrontación de varias culturas o, en términos de la teoría literaria y cultural latinoamericanas, la heterogeneidad o hibridación cultural en el subcontinente. Estos procesos, conflictos culturales y sus rasgos diferenciadores se representan sobre todo en el indianismo; en parte de la literatura costumbrista del siglo xIx; y en el indigenismo y la novela regionalista en general del siglo $\mathrm{xx}$.

Aunque Joaquim Inojosa propone una distinción entre "regionalismo urbano", "regionalismo indianista" y "regionalismo sertane-

ferner Welten. Realismus und Heterogenität in der Prosa Juan Rulfos und Manuel Scorzas, Bielefeld, Aisthesis, 1996, 188-189. 
jo" en uno de los pocos intentos de diseñar una historia de las distintas formas y fases del regionalismo para el caso de Brasil, ${ }^{7}$ las literaturas regionales y el regionalismo casi siempre se definen como literaturas de una región "interior" o "periférica”, es decir, la literatura del centro o de la metrópoli no se considera literatura regional a pesar de que lo podría ser en términos meramente geográficos.

Por lo general, tampoco se consideran las literaturas de regiones transfronterizas o supranacionales, sino el regionalismo se define, al menos hasta la década de 1980, como una literatura de provincias dentro del territorio nacional. La investigación sobre las literaturas fronterizas o de los borderlands o la sobre regiones supranacionales como la Amazonía o la región andina es reciente. ${ }^{8}$ En cambio, en el nivel subcontinental, la literatura hispanoamericana o latinoamericana se analiza en su conjunto desde los sesenta del siglo pasado. En parte, estos análisis se realizan debido al financiamiento de proyectos de investigación por la UNESCO que define en ese entonces las grandes areas del Sur o "Tercer Mundo" y fortalece la investigación sobre sus culturas. ${ }^{9}$ En parte, también son una de las expresiones de las expectativas revolucionarias en el subcontinente o de la influencia de las teorías de la dependencia sobre la crítica literaria ${ }^{10}$ que implicarían una perspectiva cultural común.

${ }^{7}$ Joaquim Inojosa, Conferências I: O regionalismo na literatura brasileira, Río de Janeiro, Livraria Editora Cátedra, 1986, 12.

${ }^{8}$ Alejandro Losada, La literatura en la sociedad de América Latina, Munich, Fink, 1987; Ana Pizarro, coord., La literatura latinoamericana como proceso, Buenos Aires, Centro Editorial de América Latina, 1985; Ana Pizarro, coord., América Latina: Palavra, literatura e cultura, 3 vols., São Paulo, Campinas, Fundação Memorial da América Latina, UNICAMP, 1993-1995.

${ }^{9}$ Esta historia cultural homogénea de América Latina se refuerza con la resolución núm. 3325 que dicta la UNESCO en París en 1966, a la que siguen las resoluciones núms. 3312 y 3321, de 1968 y 1970. Por medio de ellos, se programan una serie de reuniones para estudiar las grandes regiones culturales del mundo y la difusión de los caracteres de cada región en todas las otras. En estas resoluciones, América Latina y el Caribe son consideradas una región sobre la que se planean publicar diversos volúmenes como son América Latina en su cultura, en su literatura, en sus artes, etcétera. La UNESCO encarga a varios expertos a quienes se pide de tratar de "encarar sus trabajos a partir de este concepto de unidad", según César Fernández Moreno, ed., América Latina en su literatura, México, unEsco, Siglo XXI, 1972, 17.

${ }^{10}$ Ángel Rama, Transculturación narrativa en América Latina, 2a ed., México, Siglo XXI, 1985. 
En lo que sigue, primero quisiera ocuparme brevemente de la literatura regional que hasta ahora ha despertado poco interés por la crítica y que, por razones de una distinción entre las distintas corrientes, voy a llamar "literatura regional tradicional". Mientras que en Europa, y sobre todo en España y Francia, existen una serie de trabajos que tratan de definir esta corriente literaria, ${ }^{11}$ en América Latina, hasta hace poco, no existían intentos sistemáticos de clasificación de la misma.

En un artículo publicado en el 2004, Pedro Luis Barcia propone un esquema apropiado para analizar y criticar esta literatura basado en las definiciones tradicionales de literaturas regionales en el contexto argentino. ${ }^{12}$ Distingue las siguientes nociones de literatura regional o regionalista, respectivamente:

1. "La literatura del interior". Para Barcia, esta categoría es falsificadora porque constata una homogeneidad de toda la literatura argentina no escrita en Buenos Aires sin considerar las diferencias entre las provincias y las demás regiones del país.

2. "La literatura provincial". Esta categoría es reduccionista porque la literatura regional coincidiría, en este caso, con una delimitación político-administrativa y no con una definición cultural.

3. "La literatura regionalista": Barcia critica severamente esta literatura porque ella supone, según el crítico, un grado de exasperación, un acentuar, por el sufijo, de lo regional. Ve en ella un profesionalismo de lo regional, una limitación a lo regional sin considerar una influencia de o en lo universal. Este tipo de literatura convierte en regional todo lo que se produce en y sobre una región específica. Su estética es "romántica" en el sentido de basarse en la descripción del color local, en el pintoresquismo, en notas nostálgicas. Excluye todo lo ajeno y se dedica a un culto al pasado.

${ }^{11}$ Günter Scholdt, Grenze und Region. Literatur und Literaturgeschichte im Grenzraum Saarland Lothringen Luxemburg Elsaßseit 1871, Blieskastel, Gollenstein, 1996.

${ }^{12}$ Pedro Luis Barcia, "Hacia un concepto de la literatura regional", en Gloria Videla de Rivero, Marta Elena Castellino, eds., Literatura de las regiones argentinas, Mendoza, Universidad Nacional de Cuyo, 2004, 25-45. 
4. Una “verdadera literatura regional”, en cambio, se apoya, según Barcia, en material regional, pero proyecta una dimensión universal. En ella, la región es una especie de trampolín hacia otras dimensiones, una ventana al mundo. No es aislacionista ni separatista, sino integradora. En suma, "[l] a literatura regional es el nombre verdadero de la literatura, porque toda obra es regional, nace en un tiempo, en un lugar, en una región. Ahonda en el suelo del hombre y con ello se universaliza" ${ }^{13}$

Dentro de este esquema, defino como "literatura regional tradicional" lo que para Barcia sería la literatura regionalista debido a que la noción de "literatura regionalista" ya se ha reservado para otra corriente, es decir, las novelas del llamado "regionalismo" (Güiraldes, Gallegos, el indianismo y el indigenismo, etcétera). En lo que sigue, denominaré a este regionalismo "regionalismo clásico" para distinguirlo bien de otras formas de literatura regionalista.

Lo que Barcia llama una "verdadera literatura regional" en realidad se basa en la frase de Tolstoi según la cual uno debe escribir la historia de su pueblo para escribir la historia de la humanidad, es decir, la historia local aparecerá como historia universal o como representación literaria de conflictos universales en un nivel simbólico. Pero esta noción de literatura regional me parece demasiado amplia, metafórica y ahistórica para poder respaldar el propósito de definir de una manera concreta la literatura regional o regionalista, respectivamente. Además, detrás de esta noción de literatura universal, se esconde una perspectiva neocolonialista que trata de aplicar las normas literarias de la literatura occidental o europea a toda la literatura mundial.

Regresamos, entonces, por un momento a lo que denomino "literatura regional tradicional". Aunque no coincido con Barcia en el uso de su categoría "literatura regionalista" para caracterizar a esta corriente, estoy de acuerdo con él en la descripción y crítica de ella. Se trata, en grandes rasgos, de una literatura que conserva una perspectiva nostálgica e idílica sobre regiones agrarias, una literatura im-

${ }^{13}$ Op. cit., p. 43. 
pregnada por la descripción del color local, el paisajismo, las figuras arquetípicas, y una caracterización muchas veces positivista de las relaciones humanas y de la naturaleza. Se trata, en suma, de una literatura que sobreestima las características específicas de una región y que al mismo tiempo subestima las relaciones culturales, políticas y económicas con otras regiones tanto en el nivel nacional como internacional. Una literatura que niega los procesos de migración y los intercambios de cualquier tipo, una literatura, en fin, que niega toda hibridación, transculturación o heterogeneidad cultural. En el nivel formal, sigue los modelos del realismo y el naturalismo decimonónicos, y en muchos casos comprende formas líricas para destacar el idilio.

¿Cuáles son las características más importantes de lo que denomino "regionalismo clásico"? Existen algunas semejanzas entre esta corriente y la literatura regional tradicional: la descripción de regiones agrarias y de la vida en el campo, la representación de figuras arquetípicas, una influencia de ideas positivistas o hasta racistas (como, por ejemplo, en las obras del indigenista boliviano Alcides Arguedas), el afán de representar lo autóctono, y el empleo de los recursos estilísticos tradicionales del realismo y el naturalismo. Y, por supuesto, hay también mezclas entre estos dos tipos de literatura regional o regionalista, como, por ejemplo, en las novelas del escritor mexicano Mauricio Magdaleno.

Por otra parte, el regionalismo "clásico" se distingue de la "literatura regional tradicional" por su perspectiva ideológica hacia la identidad nacional y por su representación de conflictos políticos, históricos y culturales más allá de la región en que se lleva a cabo la trama del texto. Es decir, a diferencia de la literatura regional tradicional, en la literatura del regionalismo "clásico", la identidad no se construye desde y para la región, sino o bien desde el centro describiendo la región o desde la región en vista de un concepto de identidad más amplio. Se trata, entonces, de la construcción de una identidad nacional en vez de una identidad regional.

Pero quizá el aspecto más importante del regionalismo "clásico" es su afán de representar lo autóctono. Percibo en esta corriente una contradicción interna que se impone a toda la representación litera- 
ria. Por una parte, el interior de los respectivos países se representa como la cuna de la identidad nacional, el lugar del origen, el centro de la "verdadera" identidad cultural, y como el marcador de la diferencia identitaria con respecto a la conquista, la colonización y la dependencia económica, cultural y política. Por otra, este lugar del origen cultural se presenta también como el núcleo de la barbarie que tiene que superarse para llegar plenamente a la modernidad y al desarrollo socioeconómico deseados. Esta oposición se traduce también a las representaciones frecuentes de las diferencias entre ciudad y campo. Las novelas del regionalismo "clásico" se convierten de esta manera en un campo de batalla simbólico entre civilización y barbarie, entre modernidad y diferencia.

La representación de la región en el regionalismo "clásico" es altamente simbólica y abstracta. Se trata, entonces, menos de una literatura regional en sentido estricto, sino de una alegoría nacional tal como la define Fredric Jameson en su artículo "Third-World Literature in the Era of Multinational Capitalism". ${ }^{14}$ El regionalismo "clásico" incluso sobreestima las relaciones políticas y culturales en el nivel nacional y destaca -en contra de las lecturas y las escrituras universalistas- la diferencia de esta cultura nacional con otras culturas nacionales. La región, en caso de que exista en esta corriente literaria más allá del lugar de la trama o del paisaje de fondo, es el lugar simbólico de la realización de esta diferencia. No es, por eso, un lugar concreto e histórico, sino el lugar alegórico de la definición de la identidad.

La perspectiva regionalista está encerrada en su antiuniversalismo -en su vertiente conservadora-o en su estimación de la resistencia cultural, étnica, etcétera -en su vertiente progresista-.

En lo estilístico, las obras del regionalismo "clásico" muchas veces se orientan en los modelos realistas y naturalistas, pero al mismo tiempo, se convierten en lo que Juan Loveluck ha denominado "novelas impuras", ${ }^{15}$ es decir, combinan la trama novelística con párra-

${ }^{14}$ Fredric Jameson, “Third-World Literature in the Era of Multinational Capitalism”, en Social Text 15, 1986, 65-88.

${ }^{15}$ Juan Loveluck, "Introducción: Crisis y renovación de la novela hispanoamericana”, en Juan Loveluck, ed., La novela hispanoamericana, $4^{\mathrm{a}}$ ed., Santiago de Chile, Edito- 
fos meramente ensayísticos, discursos políticos, panfletos, pasajes líricos, glosarios explicativos, etcétera. Su lenguaje trata de ser más fiel al lenguaje hablado y a las expresiones provenientes de lenguas indígenas o expresiones locales que el de la literatura del siglo XIX. Son precisamente los elementos "impuros" que les han merecido una fuerte e injusta crítica por parte de los representantes de la llamada "nueva novela hispanoamericana" (Carlos Fuentes y Mario Vargas Llosa, sobre todo). ${ }^{16}$

No obstante estas críticas, no debemos olvidar que el regionalismo "clásico", sobre todo en su vertiente indigenista, ${ }^{17}$ se convirtió en un instrumento de crítica social y política importante en las primeras décadas del siglo xx. Y aunque se haya destacado el peligro de sobreestimar el regionalismo "tradicional", estéticamente poco interesante, simplemente por sus rasgos regionales o locales, no debemos olvidar que la consideración de esta corriente puede significar una contextualización de la praxis social característica de ciertas regiones. Las literaturas regionales o regionalistas de vez en cuando sirven también como documentos históricos de la vida en las respectivas regiones por falta de una historiografía regional o una microhistoria para las épocas referidas.

Además, el problema de la construcción de la identidad, sea esa nacional, transnacional, regional, étnica, etcétera, sigue vigente. Lo muestran no solamente los conflictos políticos actuales en varios países de América Latina, sino se percibe también, en el nivel de los debates culturales y literarios del siglo xx en el subcontinente. Un ejemplo vivo de estos debates son las "eternas" polémicas entre posturas regionalistas y universalistas entre varios literatos y grupos de escritores. Desde el debate entre José Carlos Mariátegui y Luis Al-

rial Universitaria, 1972, 11-31, especialmente 12-17. Cfr., para una crítica de esta postura, Friedhelm Schmidt, Stimmen ferner Welten. Realismus und Heterogenität in der Prosa Juan Rulfos und Manuel Scorzas, Bielefeld, Aisthesis, 1996, 188-189.

${ }^{16}$ Carlos Fuentes, La nueva novela hispanoamericana, México, Joaquín Mortiz, 1969; Mario Vargas Llosa, "Novela primitiva y novela de creación en América Latina", en Revista de la Universidad de México, 23, 10, 1969, 29-36.

${ }^{17}$ Cfr., sobre todo con respecto a la "anatomía" de este indigenismo, Estelle Tarico, The Inner Life of Mestizo Nationalism, Minneapolis, Londres, University of Minnesota Press, 2008, 1-29. 
berto Sánchez y la polémica entre los Contemporáneos y los escritores de la novela de la Revolución mexicana hasta la polémica entre José María Arguedas y Julio Cortázar o los debates actuales sobre el carácter universalista o regionalista de la literatura mexicana de la frontera norte, se puede percibir que este problema no está resuelto -como tampoco está resuelta la cuestión de la territorialidad de la cultura o la literatura en tiempos de la cuarta fase de globalización y la existencia de comunidades transnacionales-.

Quisiera mencionar brevemente una tercera corriente de literatura regional o regionalista, la que denomino el "regionalismo no nostálgico". Se puede tratar tanto de la literatura de una región interna de un país o de una región supranacional -por ejemplo, de la literatura andina o la de regiones fronterizas (borderland cultures)-, es decir, esta noción no tiene que limitarse al esquema de las literaturas nacionales. En comparación con el regionalismo "clásico" no representa a la nación como unidad nacional y territorial, sino se trata de una representación -sea esta abstracta, simbólica o concreta-, de la heterogeneidad o la hibridación cultural y social, de los conflictos internos y externos de las regiones representadas, es decir, los conflictos étnicos, políticos, internacionales, etcétera.

En general, esta corriente literaria trata de estimar el desarrollo específico de una región, muchas veces su marginación, pero sin la perspectiva nostálgica, paisajista o pintoresca que caracteriza al regionalismo tradicional. Esta corriente se ocupa de una representación realista del campo y sus problemas, de la situación fronteriza, y de los diferentes niveles de conflictos sociales (local, regional, nacional, internacional). En lo formal, son característicos los modelos modernos y posmodernos, la modernización literaria mediante técnicas vanguardistas o posvanguardistas, y la integración de formas literarias locales o indígenas (hasta en el nivel semántico, como en el caso de José María Arguedas), y la influencia de la oralidad y otras características de las diferentes culturas de la región, es decir, la consideración de los procesos de transculturación.

Un caso emblemático de este regionalismo no nostálgico es la obra de Juan Rulfo, pero también se pueden incluir los textos de algunos neoindigenistas como José María Arguedas, Rosario Caste- 
llanos o Manuel Scorza, los de escritores de la literatura del noreste del Brasil, o los de autores "fronterizos" del norte de México como Cristina Rivera Garza, Daniel Sada, David Toscana, entre otros.

Para terminar, quisiera dar énfasis en un punto débil de este artículo sobre diferentes regionalismos literarios. Por razones de tiempo y espacio, pero también por razones de mi propia ignorancia, solamente hablé de algunas corrientes de uno de los (al menos) tres sistemas literarios existentes en América Latina, es decir, me ocupé exclusivamente de la llamada "literatura culta". No traté las literaturas populares ni aquellas en lenguas indígenas que abarcan un sinnúmero de textos literarios, desde los narcocorridos, hasta la literatura oral en quechua o mapundung, por ejemplo. Si me hubiera ocupado de estos dos sistemas literarios, las nociones de regionalismo literario, sus relaciones con otras corrientes literarias y sus interdependencias serían, sin duda alguna, mucho más complejas que las que presenté brevemente en este trabajo.

Otro aspecto que no pude analizar aquí es el de la regionalización, que en gran parte va más allá del análisis literario en sentido estricto. La regionalización literaria es, primordialmente, un fenómeno de la política editorial, de la traducción, de las políticas culturales, de la difusión de la literatura en instituciones culturales, y hubiera sido una tarea demasiado ambiciosa analizar estos aspectos del sistema literario en este breve texto.

\section{BibLIOGRAFÍA}

Alonso, Carlos J., The Spanish American Regional Novel. Modernity and Autochthony, Cambridge, Cambridge University Press, 1990.

"The Criollista Novel" en Roberto González Echevarría, Enrique Pupo-Walker, eds., The Cambridge History of Latin American Literature. Volume 2: The Twentieth Century, Cambridge, Nueva York, Melbourne, Cambridge University Press, 1996, 195-212.

BARCiA, Pedro Luis, "Hacia un concepto de la literatura regional" en Gloria Videla de Rivero, Marta Elena Castellino, eds., Literatura 
de las regiones argentinas, Mendoza, Universidad Nacional de Cuyo, 2004, 25-45.

Fernández Moreno, César, ed., América Latina en su literatura, México, unesco, Siglo XXI, 1972.

Fuentes, Carlos, La nueva novela hispanoamericana, México, Joaquín Mortiz, 1969.

Inojosa, Joaquim, Conferências I: O regionalismo na literatura brasileira, Río de Janeiro, Livraria Editora Cátedra, 1986.

JAMESON, Fredric, "Third-World Literature in the Era of Multinational Capitalism”, en Social Text 15, 1986, 65-88.

Kristal, Efrain, "Del indigenismo a la narrativa urbana en el Perú", en Revista de Critica Literia Latinoamericana, 14, 27, 1988, 57-74.

LosADA, Alejandro, La literatura en la sociedad de América Latina, Munich, Fink, 1987.

LoveluCK, Juan, "Introducción: Crisis y renovación de la novela hispanoamericana”, en Juan Loveluck, ed., La novela hispanoamericana, $4^{\mathrm{a}}$ ed., Santiago de Chile, Editorial Universitaria, 1972, 11-31.

Oviedo, José Miguel, Historia de la literatura hispanoamericana. 3. Postmodernismo, vanguardia, regionalismo, Madrid, Alianza, 2001.

Pizarro, Ana, coord., La literatura latinoamericana como proceso, Buenos Aires, Centro Editorial de América Latina, 1985. , coord., América Latina: Palavra, literatura e cultura, 3 vols., São Paulo, Campinas, Fundação Memorial da América Latina, UNICAMP, 1993-1995.

Rama, Ángel, Transculturación narrativa en América Latina, 2a ed., México, Siglo XXI, 1985.

Schmid, Friedhelm, Stimmen ferner Welten. Realismus und Heterogenität in der Prosa Juan Rulfos und Manuel Scorzas, Bielefeld, Aisthesis, 1996.

Scholdt, Günter, Grenze und Region. Literatur und Literaturgeschichte im Grenzraum Saarland Lothringen Luxemburg Elsaßseit 1871, Blieskastel, Gollenstein, 1996.

TARICO, Estelle, The Inner Life of Mestizo Nationalism, Minneapolis, Londres, University of Minnesota Press, 2008. 
Vargas Llosa, Mario, "Novela primitiva y novela de creación en América Latina", en Revista de la Universidad de México, 23, 10, 1969, 29-36.

Videla de Rivero, Gloria, Marta Elena Castellino, eds., Literatura de las regiones argentinas, Mendoza, Universidad Nacional de Cuyo, 2004.

FECHA DE RECEPCIÓN DEL ARTíCULO: 27 de enero de 2010

FECHA DE ACEPTACIÓN Y RECEPCIÓN DE LA VERSIÓN FINAL: 31 de marzo de 2011 